\title{
Immobilization of biocatalysts for enzymatic polymerizations: Possibilities, advantages, applications
}

\author{
Nemanja Miletić ${ }^{\mathrm{a}}$, Aleksandra Nastasović ${ }^{\mathrm{b}}$, Katja Loos ${ }^{\mathrm{c}, *}$ \\ ${ }^{a}$ Fruit Research Institute, Kralja Petra I No. 9, 32000 Čačak, Serbia \\ ${ }^{\mathrm{b}}$ University of Belgrade, ICTM - Center for Chemistry, Polymer Department, Njegoševa 12, 11000 Belgrade, Serbia \\ ${ }^{\mathrm{c}}$ Department of Polymer Chemistry, Zernike Institute for Advances Materials, University of Groningen, Nijenborgh 4, 9747 AG Groningen, The Netherlands
}

\section{A R T I C L E I N F O}

\section{Article history:}

Received 2 September 2011

Received in revised form 13 November 2011

Accepted 14 November 2011

Available online 23 November 2011

\section{Keywords:}

Enzymatic polymerization

Biocatalysis

Polymer synthesis

Enzyme immobilization

Immobilization supports

\begin{abstract}
A B S T R A C T
Biotechnology also holds tremendous opportunities for realizing functional polymeric materials. Biocatalytic pathways to polymeric materials are an emerging research area with not only enormous scientific and technological promise, but also a tremendous impact on environmental issues. Many of the enzymatic polymerizations reported proceed in organic solvents. However, enzymes mostly show none of their profound characteristics in organic solvents and can easily denature under industrial conditions.

Therefore, natural enzymes seldom have the features adequate to be used as industrial catalysts in organic synthesis. The productivity of enzymatic processes is often low due to substrate and/or product inhibition. An important route to improving enzyme performance in non-natural environments is to immobilize them.

In this review we will first summarize some of the most prominent examples of enzymatic polymerizations and will subsequently review the most important immobilization routes that are used for the immobilization of biocatalysts relevant to the field of enzymatic polymerizations.
\end{abstract}

(c) 2011 Elsevier Ltd. All rights reserved.

\section{Introduction}

Enzymes have excellent features (activity, selectivity, specificity) for designing synthetic processes to obtain a wide range of products under mild and environmental friendly conditions.

While the chemical, economic and social advantages of biocatalysis over traditional chemical approaches were recognized a long time ago, their applications for industrial production processes have been largely neglected until recent breakthroughs in modern biotechnology (such as robust protein expression systems, directed evolution, etc.). Subsequently, in recent years, biotechnology has established itself as an indispensable tool in the synthesis of small molecules in the pharmaceutical sector including antibiotics, recombinant proteins, vaccines and monoclonal antibodies.

Biotechnology also holds tremendous opportunities for realizing functional polymeric materials. Biocatalytic pathways to polymeric materials are an emerging research area with not only enormous scientific and technological promise, but also a tremendous impact on environmental issues. However, this multidisciplinary combination is not studied extensively at this point.

At present, enzymes from 4 of the 6 EC enzyme classes are known to induce or catalyze polymerizations. An overview of the

\footnotetext{
* Corresponding author.

E-mail address: k.u.loos@rug.nl (K. Loos).
}

main enzyme classes and polymer systems studied so far is shown in Table 1 (Loos, 2010).

Many of the enzymatic polymerizations reported proceed in organic solvents. However, enzymes have been optimized, via natural evolution, to fulfill their biological function: to catalyze reactions in complex metabolic pathways exposed to many levels of regulation. On the other hand, most of them show none of their profound characteristics in organic solvents and can easily denature under industrial conditions (high temperature, solvent effects, mechanical shear, etc.).

Therefore, natural enzymes seldom have the features adequate to be used as industrial catalysts in organic synthesis. Recovery of enzymes from reaction solutions and separation of the enzymes from substrates and products are generally difficult. The productivity (space, time, yield) of enzymatic processes is often low due to substrate and/or product inhibition. An important route to improving enzymes' performance in non-natural environments is to immobilize them by either adsorption, covalent attachment or by incorporation in hydrophobic organic-inorganic hybrid materials with the help of a sol-gel process (Tischer and Wedekind, 1999; Miletic et al., 2009a; Pavlidis et al., 2010; Saunders and Brask, 2010).

In this review some of the most prominent examples of enzymatic polymerizations will first be summarized and subsequently the most important immobilization routes that are used for the immobilization of biocatalysts relevant to the field of enzymatic polymerizations will be reviewed. 
Table 1

Overview of the main enzyme classes and polymer systems studied in the field of enzymatic polymerizations.

\begin{tabular}{|c|c|c|c|}
\hline Enzyme class & Biochemical function in living systems & $\begin{array}{l}\text { Typical enzymes inducing } \\
\text { polymerization }\end{array}$ & Typical polymers \\
\hline (I) Oxidoreducates & Oxidation or reduction & Peroxidase laccase & $\begin{array}{l}\text { Polyanilines, polyphenols, polystyrene, } \\
\text { polymethyl methacrylate }\end{array}$ \\
\hline (II) Transferases & $\begin{array}{l}\text { Transfer of a group from one } \\
\text { molecule to another }\end{array}$ & $\begin{array}{l}\text { PHA synthase, hyaluronan } \\
\text { synthase, phosphorylase }\end{array}$ & Polyesters, hyaluronan, amylose \\
\hline (III) Hydrolases & Hydrolysis reaction in $\mathrm{H}_{2} \mathrm{O}$ & $\begin{array}{l}\text { Cellulase, chitinase, xylanase, } \\
\text { papain, lipase }\end{array}$ & $\begin{array}{l}\text { Cellulose, chitin, xylan, (Oligo)peptides, } \\
\text { polyesters, polycarbonates }\end{array}$ \\
\hline (IV) Lyases & Non-hydrolytic bond cleavage & & \\
\hline (V) Isomerases & Intramolecular rearrangement & & \\
\hline (VI) Ligases & Bond formation requiring triphosphate & Cyanophycin synthetase & Cyanophycin \\
\hline
\end{tabular}

\section{Enzymatic polymerizations}

The in vitro enzymatic synthesis of polymers via non-metabolic pathways is a relatively old area of precision polymer synthesis. The enzymatic polymerization of polysaccharides was for instance already reported more than 60 years ago. However, other polymerization methods using cheap petroleum based monomers soon replaced research on biocatalytic polymerization techniques.

These days fast depletion of the petroleum stock and increase in the cost of petroleum based monomers puts limit to their use in the future and enzymatic polymerizations are currently facing a renaissance. Recently some helpful reviews (Gross et al., 2001; Kobayashi and Makino, 2009) and books (Kobayashi et al., 2006; Loos, 2010; Cheng and Gross, 2010; Palmans and Heise, 2010) were published that give a good introduction to the field of enzymatic polymerizations.

Among the enzymes used successfully for polymer synthesis, Candida antarctica lipase B (CALB) is by far the most well-known enzyme in literature. In most reported enzymatic polymerizations it is used as an immobilized enzyme. Novozym 435 is a commercially available heterogeneous biocatalyst that consists of CALB physically immobilized within a macroporous resin of poly(methyl methacrylate) (Saunders and Brask, 2010).

Polyesters are in widespread use in modern life, ranging from bottles for carbonated soft drinks and water, fibers for shirts and other apparel, to the base for photographic film and recording tape. Among enzymes, lipases proved to be the most efficient for the in vitro polyester synthesis. CALB (Novozym 435) is capable of catalyzing a range of organic chemical reactions, including polyester synthesis by ring-opening polymerization of various lactones and polycondensation reactions of diacid/diol substrates.

Lipases or triacylglycerol acylhydrolases are water-soluble enzymes that catalyze the hydrolysis of ester bonds in water-insoluble, lipid substrates, and therefore comprise a subclass of the esterases. Lipases are ubiquitous enzymes of considerable physiological significance and perform crucial roles in the digestion, transport and processing of dietary lipids in most of living organisms. Thus, lipases can be found in diverse sources, such as plants, animals, and microorganisms. More abundantly, they are found in bacteria, fungi and yeasts. Lipases catalyze the hydrolysis of relatively long chain triglycerides (with acyl chain lengths of over ten carbon atoms) to the corresponding diacylglyceride, monoacylglyceride, glycerol and fatty acids. Since the water insoluble lipid interferes with the water soluble lipase, digestion of these triglycerides takes place at the water-oil interface. On the other hand, it is well known that the reaction is reversible and lipases can catalyze ester synthesis and transesterification in the reaction containing low water concentrations opening up the possibility to synthesize polyester.

The in vitro polyester synthesis can proceed via two major polymerization modes (Gross et al., 2001; Uyama and Kobayashi, 2006; Miletić et al., 2010b):
(1) Polycondensation between a carboxyl group and an alcohol group, and

(2) Ring-opening polymerization (ROP).

Okumara et al. (1984) were the first to attempt the enzymecatalyzed synthesis of oligoesters from a reaction between dicarboxylic acids and diols. Gutman et al. (1987) reported the first study on polyester synthesis by enzyme-catalyzed polymerization of A-B type monomers. Two independent groups in 1993 (Knani et al., 1993; Uyama and Kobayashi, 1993) were first to report enzyme-catalyzed ring-opening polymerization (ROP). Their studies focused on 7- and 6-membered unsubstituted cyclic esters $\varepsilon$-caprolactone and $\delta$-valerolactone, respectively.

A variety of in vitro polyester synthesis reactions have been developed in the last couple of decades and a couple of excellent reviews on this topic has been published (Gross et al., 2001; Kobayashi and Makino, 2009; Palmans and Heise, 2010; Miletić et al., 2010b).

Polyamides are versatile engineering plastics and excellent fiber materials due to their toughness over wide ranges of temperatures. Polyamides are synthesized via two main methods: (a) polycondensation of diacid and diamine, and (b) ring opening polymerization of lactams. While there are many reports on enzymatic polyester formation, there are, surprisingly, only few publications on enzyme-catalyzed synthesis of polyamides which were recently reviewed in an excellent review (Cheng, 2010).

Vinyl monomers can also be polymerized via an enzyme initiated polymerization (Hollmann, 2010). Most studies conducted so far are based on the polymerization of acrylamide and styrene as model compounds. Among the various radical-forming enzyme systems peroxidases and (to a lesser extend) laccases have been used as bio-initiators. The biocatalyst of choice for these works clearly is the peroxidase from horseradish (HRP). Other catalysts such as soybean peroxidase, manganese peroxidase or hematin have been used scarcely.

The excellent features of peroxidases for this type of enzymatic polymerization originate from their natural function as radical initiators for lignin degradation and defense against pathogens via reactive radical species. Ferriprotoporphyrin constitutes the catalytically active prosthetic group of the predominant heme-dependent peroxidases. Peroxidases and laccases catalyze an overall hydrogen abstraction (either as such or in a sequence of single electron transfer and deprotonation) from their respective substrates producing the initiator radical. The reducing equivalents liberated from the initiator precursor are transferred to suitable electron acceptors. In case of peroxidases, hydrogen peroxide serves as electron acceptor, whereas laccases utilize molecular oxygen. In both cases water is the final product (Hollmann, 2010).

Besides acrylamide and styrene the enzyme initiated polymerization of for instance methyl methacrylate (MMA), hydroxyethylmethacrylate (HEMA), substituted styrene, etc. using peroxidases and laccases is reported as well (Hollmann, 2010). 
Peroxidases and laccases can also be used as catalyst for enzymatic oxidative polymerizations of phenol derivatives to produce novel polyaromatics and the enzymatic polymerization of electrically conducting polymers such as polyaniline. More details can be found in some recent excellent reviews (Uyama, 2010; CruzSilva et al., 2010).

Polysaccharides can be quite elegantly synthesized by enzymatic polymerizations as well (van der Vlist and Loos, 2010a,b). Conventional chemical synthetic approaches are, in many cases, inadequate to provide substantial quantities of saccharides. The difficulties arise from realizing complete regio and stereo-control of the glycosylating process. Enzymatic polymerizations are therefore a superior alternative.

Two approaches have dominated enzyme-catalyzed saccharide synthesis: glycosyl transferase and glycosidase-catalyzed glycosidic bond formation. (van der Vlist and Loos, 2010a,b) The first uses the normal biosynthetic machinery of living organisms. In the second, enzymes that normally catalyze transfer of an enzyme-bound glycosyl residue to water are induced to transfer it instead to a different acceptor.

By making use of the biosynthetic glycosyl transferases, it is possible to glycosylate carbohydrate substrates. A sugar nucleotide donor and acceptor are incubated with the appropriate glycosyl transferase that catalyzes efficient and selective transfer of the glycosyl residue to the acceptor. This method has the advantage of high efficiency and selectivity. Its major drawbacks are the requirement for a complex glycosyl donor and the relative inaccessibility of the glycosyl transferases.

Glycosidases (also called glycoside hydrolases; EC 3.2.1) catalyze the hydrolysis of the glycosidic linkage to generate smaller sugars. Together with glycosyltransferases, glycosidases form the major catalytic machinery for the synthesis and breakage of glycosidic bonds. The native action of glycosidases is to hydrolyze glycosidic linkages of glucans in the presence of water. These types of enzyme catalyzed reactions are reversible and hence the glycosidic bond formation is possible if the glycosyl substrate (the monomer) has a good leaving group and if the reaction conditions, with respect to substrate concentration, temperature and solvent quality, are well chosen. With this it became possible to synthesize in vitro natural polysaccharides such as cellulose, xylan, chitin, hyaluronan and chondroitin, and also of unnatural polysaccharides such as a cellulose-chitin hybrid, a hyaluronan-chondroitin hybrid, and others.

In contrast to the glycosyl transferases, the glycosidase approach uses simpler glycosyl donors which in the limit, can be the free monosaccharide. This method has the advantage of using relatively simple glycosyl donors and readily available robust enzymes. Its main disadvantage is that regioselectivity may not be observed in all cases.

The most extensively studied system in the field of enzymatic polymerizations is the lipase catalyzed polymerization of polyesters. Therefore the immobilization of various lipases is the most active and intriguing field of research in the context of our current review. The following part on the immobilization of enzymes that are used in enzymatic polymerizations is therefore focused nearly exclusively on lipases. As the field of enzymatic polymerization develops we are sure that soon more efforts on immobilizing other enzyme classes used for polymerizations will be published.

\section{Background on enzyme immobilization}

Enzyme immobilization was first introduced to enable the reuse of costly enzymes. Some of the initial attempts to do this were described during the early parts of the last century (Hedin, 1915), but the enzymes when adsorbed to charcoal proved to be very unstable. Around the 1950s, several groups began to immobilize enzymes onto other supports (Micheel and Ewers, 1949; Grubhofer and Schleith, 1954). Manecke was one of the first to succeed in making relatively stable immobilized systems of proteins on polymer supports (Manecke and Singer, 1960). The first industrial applications of immobilized enzymes were in the production of optically pure amino acids (Tosa et al., 1969) and the hydrolysis of penicillin G (Carleysmith and Lilly, 1979). Since then a lot of research has been conducted (Tischer and Wedekind, 1999; Gross et al., 2001; Krajewska, 2004; Miletić et al., 2009b; Pavlidis et al., 2010; Saunders and Brask, 2010).

The main advantages of immobilization are: (i) increased enzyme activity (up to a factor of 100) in organic solvents; (ii) increased temperature stability; (iii) remarkable long-term stability; (iv) increased enantioselectivity; (v) the ease with which the enzyme can be recovered after the reaction by filtration or centrifugation; (vi) reusability of the enzymes even in another type of reaction.

There are different ways to establish immobilization, often classified by the type of chemical reaction used for binding (Table 2).

\section{Properties of immobilized enzymes}

The properties of immobilized enzyme preparations are governed by the properties of both the enzyme and the support material. The interaction between the two provides an immobilized enzyme with specific chemical, biochemical, mechanical and kinetic properties (Fig. 1).

The biochemical properties of the enzyme, such as its molecular mass, functional groups on the surface and its purity are important factors for immobilization. The functional groups on the surface of the enzyme for instance give information on which kind of interactions between the support and the enzyme can take place. Also the purity of the enzyme is important, since the impurities can interfere with the substrates.

Other features of the enzyme that determine the parameters of the immobilized enzyme are the reaction type and the kinetics of the reaction that is catalyzed by the enzyme. Specific activities, kinetic parameters for activation and inhibition and stability against $\mathrm{pH}$, temperature, solvents and impurities have impact on the immobilized enzyme as well.

The characteristics of the support material also influence the properties of the immobilized enzyme. One of the most important features of the support is the chemical structure that will determine interaction with enzymes. If the support material is highly porous, pore size and pore size distribution will play an important role in determining the immobilized enzyme properties. A small pore size can cause diffusion limitation resulting in structural rearrangement of the enzymes and subsequent inactivity. However, for very large pore sizes enzymes can cluster together and thus lose activity.

The mechanical properties of the support material are crucial in the application of the immobilized enzyme. When an immobilized enzyme is applied in a stirred tank, it has to have other properties

Table 2

Methods used to immobilize enzymes.

\begin{tabular}{ll}
$\begin{array}{c}\text { Non-covalent } \\
\text { binding }\end{array}$ & $\begin{array}{l}\text { Adsorptive or ionic binding onto support materials } \\
\text { Enzyme crystallization } \\
\text { Dispersing enzymes (e.g. dried enzyme powders in } \\
\text { organic solvents) }\end{array}$ \\
Covalent binding & $\begin{array}{l}\text { Binding onto prefabricated support materials } \\
\text { Cross linking }\end{array}$ \\
Inclusion & $\begin{array}{l}\text { Incorporation into polymeric networks } \\
\text { Incorporation into membrane device } \\
\text { Inclusion into membrane device }\end{array}$ \\
\hline
\end{tabular}




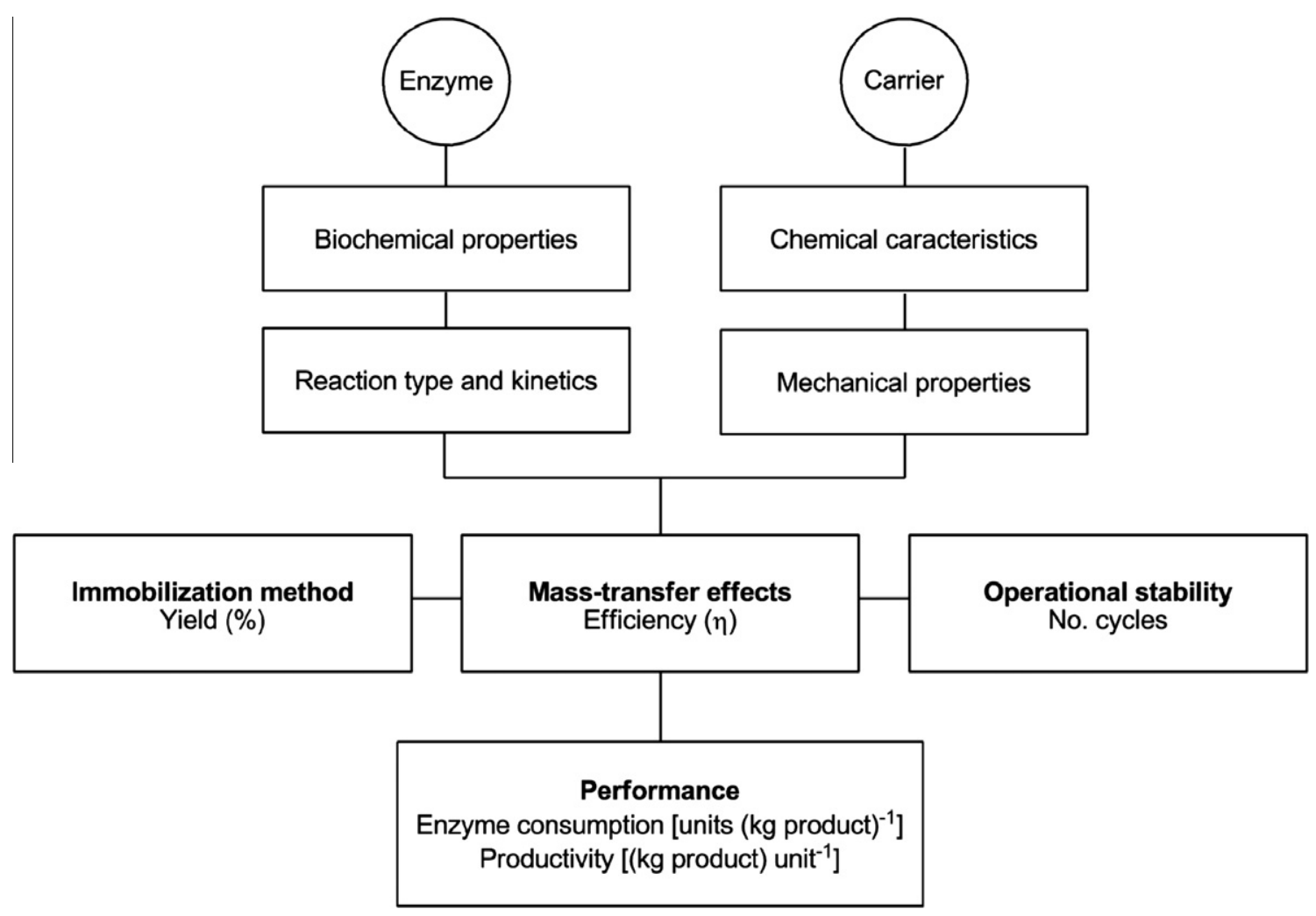

Fig. 1. Properties of enzyme and support determine the properties of the immobilized enzyme (Tischer and Wedekind, 1999).

than when it is applied in a column. In a stirred tank, the support material must be resistant to abrasion, while in a column it has to have some flow resistance.

Support particle size is also significant. An example of the influence of particle size on the distribution of enzyme throughout the support bead is given by Chen et al. (2007a). They examined the CALB immobilization on methyl methacrylate resins with identical average pore diameter $(250 \AA)$ and surface area $\left(500 \mathrm{~m}^{2} / \mathrm{g}\right)$ but with varied particle size ( 35 to $560-710 \mu \mathrm{m}$ ). A non-uniform distribution with most enzymes present in the outer region of particles was found by infrared microspectroscopy with 560-710 and $120 \mu \mathrm{m}$ diameter resins. In contrast, as the resin particle size was decreased, the protein distribution became increasingly uniform throughout resins (Fig. 2).

When the characteristics of the enzyme and support are combined, some other features also influence the properties of the immobilized enzyme.

The immobilization method and optimization of immobilization conditions are also crucial for biocatalyst properties ( $\mathrm{pH}$, temperature, time of immobilization, etc.), and therefore should be chosen with special care (Zhang et al., 2010).

The rate of the enzyme-catalyzed reaction is greatly influenced by mass-transfer effects. Due to mass transfer to, from and inside the immobilized enzyme, micro and nano environments occur
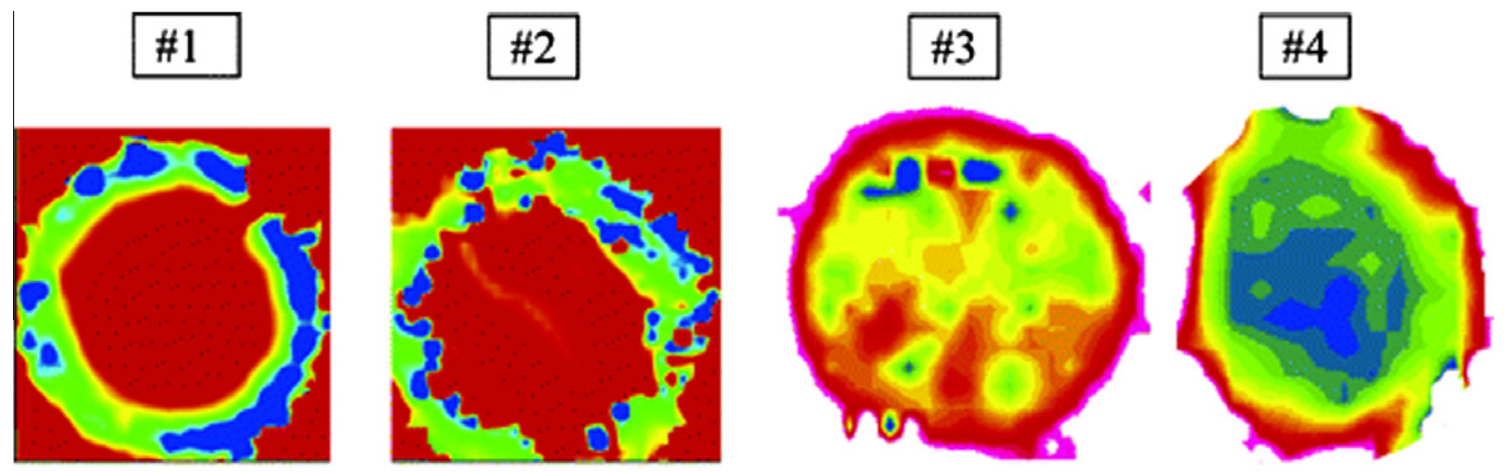

\section{Low concentration}

\section{High Concentration}

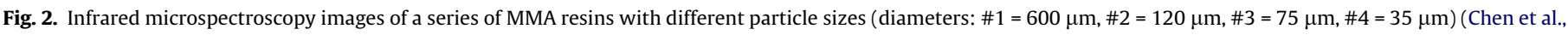
2007a). 
with different $\mathrm{pH}$, concentration, etc. This effect arises from the fact that an immobilized enzyme is bound to the support and has a deliberate restricted mobility. It can affect the mobility of the solutes as well. The solutes can be adsorbed to the support, resulting in a reduced mobility which causes a decreased reaction rate compared with soluble enzymes (Buchholz et al., 2005).

\section{Methods of immobilization}

\subsection{Support binding - support-bound enzymes}

Support binding can be physical (such as hydrophobic, van der Waals, and ionic interactions) or covalent in nature. Physical adsorption is a simple and straightforward route for enzyme immobilization, in which the enzyme is bound to a support by hydrophobic, van der Waals or ionic interactions. It is often used because of the ease and low cost of the procedure. A support is added to an enzyme solution and after a few hours of mixing the enzyme-support complex is ready. Secondly, physical adsorption is reversible that enables the reuse of the support. Denatured enzymes can be removed from the support by changes in $\mathrm{pH}$ or ionic strength of the reaction medium and it can be replaced with fresh enzyme. However, hydrophobic and van der Waals bonding is generally too weak to keep the enzyme fixed to the support under industrial conditions of high reactant and product concentrations and high ionic strength. Therefore, the leaking of enzyme upon use can be expected, not all of the enzyme can be reused, and the product might have to be purified. On the other hand, ionic and covalent binding are generally stronger due to the firm bonding between the enzyme and the support, which have the advantages that the biocatalysts do not suffer from desorption or leaching of enzymes during catalytic reactions. Nevertheless, enhancement of the bond strength between the enzyme and the support can cause changes in the enzyme conformation, often into a less favourable one, which can result in deactivation of the enzyme. Moreover, if the enzyme is deactivated (or denatured), both enzyme and the support remained unusable.

Physical adsorption is best suited to immobilization of lipases for use in organic solvents, such as commercial preparations of immobilized CALB (Novozym 435, Chirazyme). Several different supports were used for the physical adsorption of lipases: polymers (Chen et al., 2007b; Santos et al., 2007), carbon nanofibers (Kovalenko et al., 2009), silica (Luckarift et al., 2004), Celite (Vulfson et al., 2001).

Octadecyl-sepabeads (Mitsubishi Chemical Corporation) were used to immobilize the lipases from C. antarctica (fraction B), Mucor miehei and Candida rugosa via interfacial adsorption (Palomo et al., 2002). The same lipases were immobilized on glyoxyl-agarose via multipoint covalent attachment (see below). Lipases adsorbed on octadecyl-sepabeads, as highly hydrophobic supports, exhibited a clear hyper-activation compared to the soluble enzyme or other types of derivatives. According to the authors, high activity is caused by the hyper-activation of the lipase due to interfacial adsorption to hydrophobic surfaces (Mateo et al., 2007a,b). The closed form of the lipase, considered inactive since the active site is isolated from the reaction medium by a polypeptide chain called the lid, is favoured in solution. But when the lipase comes in contact with a hydrophobic surface, the lid opens and the active site is fully exposed to the reaction medium because of favorable interactions and the enzyme remains in this open formation (due to the equilibrium state) that is responsible for an increase in enzyme activity.

The activity of physically adsorbed enzymes is strongly dependent on the $\mathrm{pH}$ of the solution and working temperature. C. rugosa lipase was immobilized on poly( $N$-methylolacrylamide) by physical adsorption (Santos et al., 2007). The highest productivity and activity were obtained when working at the lowest level of temperature. On the other hand, the immobilization procedure shifted the optimum $\mathrm{pH}$ for the $C$. rugosa lipase to a more alkaline value. The free lipase reached its maximum activity at $\mathrm{pH} 7.0$, falling to about $75 \%$ at $\mathrm{pH} 8.0$, while the lipase poly $(N$-methylolacrylamide)-immobilized system showed its maximum activity at $\mathrm{pH}$ values of $7.5-8.0$, retaining about $90 \%$ of its maximum activity at pH 8.5 (Fig. 3). This behavior has been well described in the literature and can be related to the partial opening of the lipase lid upon immobilization.

Ionic binding is another simple non-covalent immobilization technique. Enzymes can be bound to polysaccharide biopolymers such as, dextran, agarose and chitosan. These polymer supports may be functionalized with a variety of chemical groups to achieve ionic interaction, including quaternary ammonium, diethylaminoethyl and carboxymethyl derivatives. This method has been applied commercially for glucose isomerase production of high fructose syrup (Lalonde and Margolin, 2002). Alternatively functionalized macroporous acrylic polymer resins such as Amberlite FPC3500 (cationic) or FPA54 (anionic) can be used.

Covalent attachment is the most widely used method of enzyme immobilization, in which the enzyme is covalently bound to a support. In immobilization through covalent attachment two different global methods can be outlined: covalent attachment via long spacer arms and covalent attachment via multipoint attachments (Fig. 4). The spacer arm has the advantage of only moderately restricting the enzymes configuration, while the multipoint attachment is supposed to have a higher stability.

Typically, the $\varepsilon$-amino group of lysine (quite common amino acid in proteins) is used as the point of covalent attachment, since it is located on the protein surface, is relatively reactive and provides good bond stability (Křenkova and Foret, 2004). On the other side, supports with epoxide groups are usually selected, since the epoxide and amine groups can react under very mild conditions and form stable bond (Mateo et al., 2007a,b).

Covalent immobilization was reported by several groups (Dyal et al., 2003; Miletić et al., 2009a). Different supports are used for immobilization and most of them are activated supports with a high content of reactive groups, for example epoxy rings or activated carbonyl groups.

On the other hand, $\gamma-\mathrm{Fe}_{2} \mathrm{O}_{3}$ magnetic nanoparticles can also be used for the covalent immobilization of $C$. rugosa lipase (Dyal et al., 2003). The advantage of magnetic particles is the easy separation, simply by applying a magnetic field and furthermore the small size of the particles enables applications in biological systems.

Combination of physical adsorption and covalent linking is a useful approach for lipase immobilization (Mateo et al., 2000). The commercial epoxy support, Eupergit $C^{\circledR}$, was modified with different moieties (ethylenediamine, iminodiacetic acid, and $m$ aminophenylboronic acid) in order to synthesize the bifunctional supports, with moieties that were able to physically adsorb the enzymes (lipase from $C$. rugosa, penicillin $G$ acylase from Escherichia coli, and $\beta$-galactosidase from $A$. oryzae), and moieties that enable covalent immobilization of the enzyme. In other words, the enzyme immobilization follows the two-step mechanism: (i) enzyme physical adsorption via additional groups, introduced in the epoxy support through the modification; (ii) covalent linkages between some nucleophilic groups of the adsorbed enzyme (e.g., amino, thiol, or hydroxy groups) and the dense layer of nearby epoxy groups on the support. This two-step covalent immobilization dramatically improves the very low reactivity of epoxy groups toward non-adsorbed proteins. These bifunctional supports are suitable for covalent immobilization of enzymes following the epoxy chemistry on any type of support (hydrophobic or hydrophilic ones) under very mild experimental conditions (e.g., low ionic strength, neutral $\mathrm{pH}$ values, and low temperatures). 

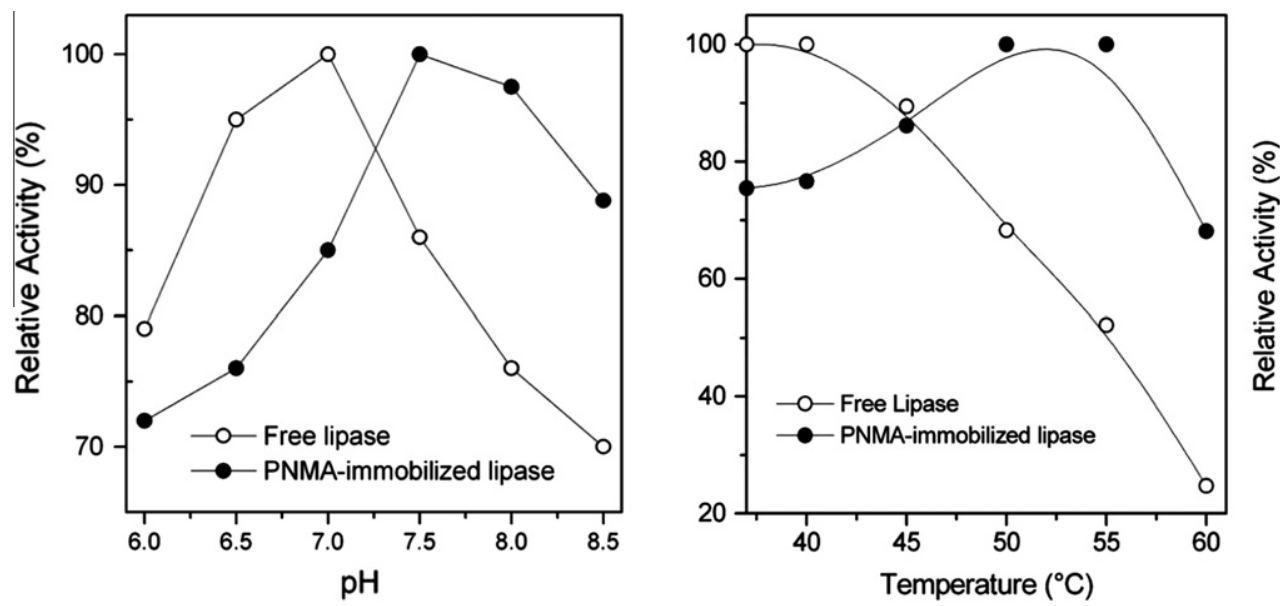

Fig. 3. Influence of $\mathrm{pH}$ and temperature on hydrolytic activity of free and poly( $N$-methylolacrylamide)-immobilized $C$. rugosa lipases (Santos et al., 2007).

A

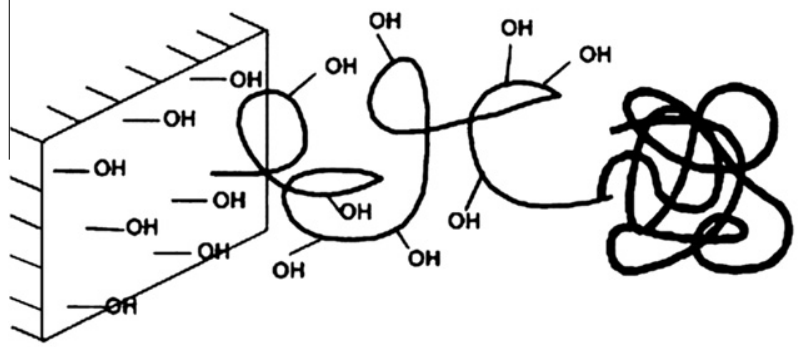

B

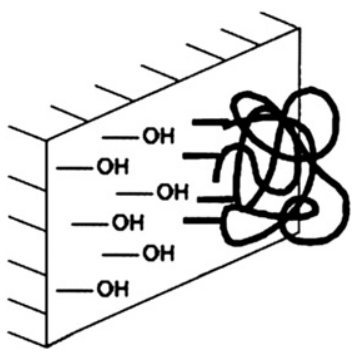

Fig. 4. Immobilization through covalent attachment: (A) via long spacer arm and (B) via multipoint attachment (Fernandez-Lorente et al., 2001).

An improved stereospecificity can also be the reason for using covalently immobilized enzymes. Lipase from Pseudomonas fluorescens showed an increased enantioselectivity upon multipoint covalent immobilization on glyoxyl-agarose. A 24 threefold improvement in the enantioselectivity was reported. According to the authors this increase is probably due to a distortion of the enzyme structure, since the activity was decreased, or/and due to an increase in rigidity of the enzyme, since the enzyme showed an increased stability (Fernandez-Lorente et al., 2001).

In some cases, the relative activities with covalent attachment are quite low. This can be explained by the fact that covalent bonding between enzyme and support restrict chain mobility within protein molecules and therefore conformational changes that are essential during catalysis are disabled. However, despite this rather low relative activity, immobilized enzymes with an activity approximately the same as the free enzyme have the potential to be used in industry. The costs saved by recovery and reuse of the enzymes can compensate for the loss of activity.

\subsection{Entrapment via inclusion}

Another possibility of enzyme immobilization is entrapment via inclusion, meaning that the enzyme is entrapped in a polymer network such as an organic polymer or sol-gel. Entrapment protects enzymes by preventing direct contact with the environment by retaining the enzymes within a device or material, but has the drawback of mass transfer limitations and low enzyme loading. Furthermore, it does not completely prevent leaking, but it considerably decreases it with regard to physical adsorption.

A common method of entrapment is through use of silica solgel matrices formed by hydrolytic polymerization. This technique is based on the production of silica matrices by acid or base catalyzed hydrolysis of silane compounds. Immobilization of the cutinase from Fusarium solani pisi, using the sol-gel matrices, prepared with a combination of alkyl-alkoxysilane precursors of different chain-lengths, has been reported (Vidinha et al., 2006). It was shown that the type and combination of silica precursors had a great influence on cutinase activity (Fig. 5). When only tetramethoxysilane (TMOS) was used, no enzyme activity was observed. When TMOS was combined with a similar monoalkylated precursor, the enzyme activity increased with increasing alkyl chain up to a certain point, decreasing from there on.

Reetz et al. have established a method that enables the immobilization of lipases via inclusion in sol-gel materials. They studied the effects that several parameters (water content, type and amount of catalyst, variation of the precursor, etc.) have on the stability and enzyme activity. They have examined several lipases and several sol-gel materials with and without additives (Reetz et al., 1995).

The immobilization of enzymes by entrapment in sol-gelderived materials has turned out to be generally applicable to a wide variety of lipases resulting in significantly increased enzyme activity in an organic medium. One likely reason for the unusually high relative enzyme activity is the high dispersion of the lipase in the sol-gel matrix. An additional factor may be a possible interaction between the lipophilic domains of the lipases and the hydrophobic regions of the organic/inorganic sol-gel matrix. Enantioselectivity studies with sol-gel encapsulated lipases were also performed (Reetz et al., 2003). Lipases (C. antarctica type B, C. rugosa, M. miehei, Aspergillus niger, Burkholderia cepacia, P. fluorescens, $C$. rugosa type VII, Penicillium roqueforti, and Thermomyces lanuginosa) were encapsulated in sol-gel materials produced by the fluoride-catalyzed hydrolysis of mixtures of tetramethyl orthosilicate $\left(\mathrm{Si}\left(\mathrm{OCH}_{3}\right)_{4}\right)$ and alkylsilanes $\left(\mathrm{RSi}\left(\mathrm{OCH}_{3}\right)_{3}\right)$. This involves 


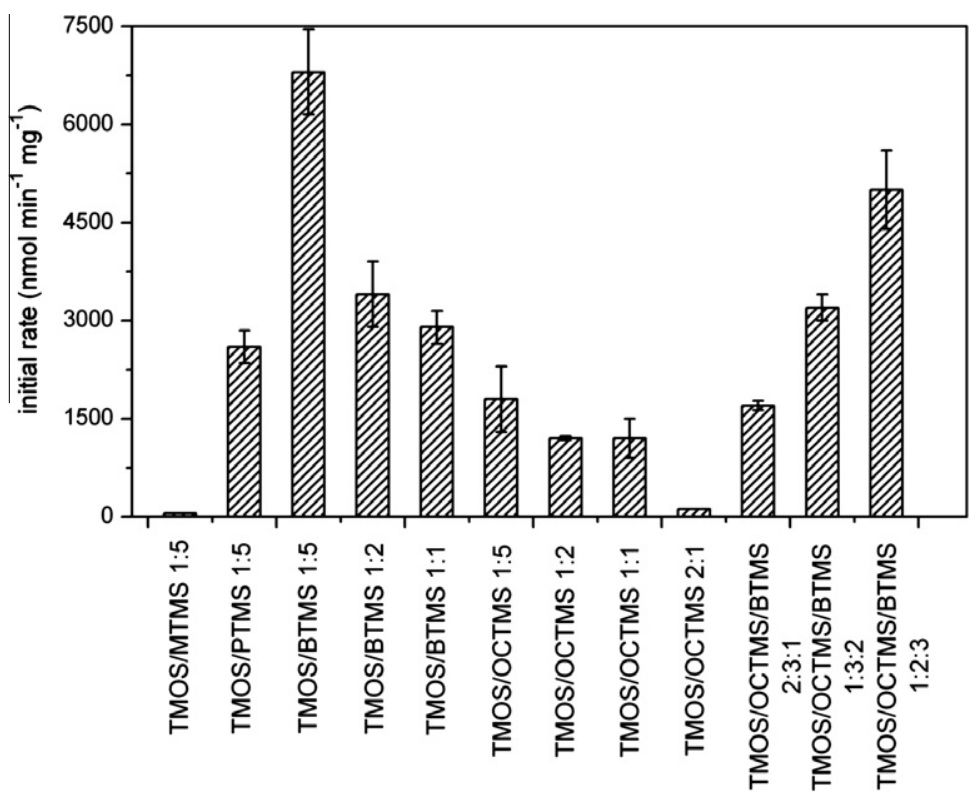

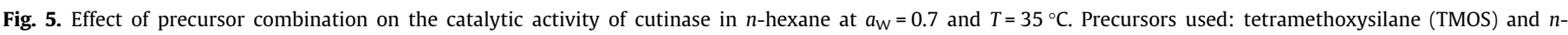

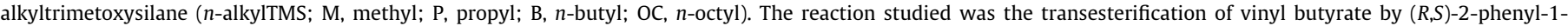
propanol (Vidinha et al., 2006).

higher enzyme loading, variation of the alkylsilane precursor, and the use of additives. All lipases tested showed significantly improved performance, although in two cases additive effects were not observed. Hwang et al. (2011) fabricated organic-inorganic hybrid microspheres for a magnetically separable enzyme entrapment system. These organic microspheres, obtained from electrospraying followed by a modified sol-gel method, are composed of PVP-alginate polymers blended and the crosslinked enzymes coated on the surfaces of magnetic beads. These enzyme systems proved to be highly stable for more than 120 days with about $75 \%$ of the initial activity preserved. Zhang et al. (2009) have recently developed an elegant method of $\beta$-glucuronidase entrapment and encapsulation in biomimetric alginate/protamine/silica capsules. It was shown that the thermal and $\mathrm{pH}$ tolerance, storage and recycling stability of encapsulated enzyme were significantly improved.

Enzyme entrapment is also possible with polymers which are nor silicon-based. Glucose oxidase was entrapped in nano- and microscale polyaniline particles (Nemzer et al., 2010). It was shown that the final morphology and optical properties are sensitive to the relative amounts of polymer, solvent, cosolvent, ions, and enzyme.

\subsection{Enzyme crosslinking}

Support-free enzyme immobilization is possible using bifunctional cross-linkers, such as glutaraldehyde, to bind enzymes to each other without resorting to a support. Plenty of supportless techniques are being developed, such as cross-linked dissolved enzymes (CLEs), cross-linked enzyme crystals (CLECs), cross-linked enzyme aggregates (CLEAs), and cross-linked spray-dried enzyme (CLSDs), being discriminated from each other only by the precursors used for cross-linking.

Insoluble cross-linked enzymes systems (CLEs) were discovered in the in the 1960s, by cross-linking of dissolved enzymes via reaction of enzyme surface amine groups with a bifunctional chemical cross-linker (Quiocho and Richards, 1966). Due to the plenty of drawbacks (low activity retention, low mechanical stability, etc.), this method was abandoned.
Cross-linked enzyme crystals (CLECs) were firstly obtained also in the 1960s, by cross-linking of crystalline enzyme by glutaraldehyde (Quiocho and Richards, 1964). CLECs are highly active immobilized enzyme systems, with controllable particle size varied from 1 to $100 \mu \mathrm{m}$. Compared to the free enzyme powder, CLECs are more stable to heat and organic solvents (Roy and Abraham, 2004). Due to the easy recycling and possible reusability, these biocatalysts are suitable for industrial application. Anyhow, this immobilization method is only applicable for the highly purified crystallisable enzymes, and moreover it is very costly method.

A simple and less-expensive method of cross-linking is the precipitating of enzymes by adding of salts, water-miscible organic solvents or non-ionic polymers to aqueous enzyme solution, and subsequent cross-linking the freshly formed aggregates, to form particles of about $50-100 \mu \mathrm{m}$ diameter, was developed by Cao et al. (2003). CLEAs of penicillin acylase (Pchelintsev et al., 2009), Pseudomonas putida nitrilase (Kumar et al., 2010), laccases (Matijošytè et al., 2010), etc. were reported.

Strategic procedure, so called 'ship-in-a-bottle' was employed by Lee et al. (2009) to develop the CLEA of $\alpha$-chymotrypsin in superparamagnetic hierarchically ordered mesocellular mesoporous silica (M-HMMS) (Fig. 6). The initial step is the enzyme adsorption in M-HMMS, resulting in a high degree of enzyme loading within a short time. The second step is the glutaraldehyde treatment, which crosslinks the adsorbed enzyme molecules to create nanometer-sized CLEA within the pores of M-HMMS. Developed CLEA of $\alpha$-chymotrypsin is highly stable and active enzyme system with an advantageous feature of magnetic separability.

Due to the relatively low activity (compared to the CLEAs, CLECs, and support-bound immobilized enzymes) and the fact that spray-drying process reversibly deactivates the enzymes, CLSDs systems are not in the research focus.

\section{Supports}

Since most of the immobilization methods require a support, and the properties of the immobilized enzymes are strongly determined by the support used (Fig. 1), therefore immobilization 

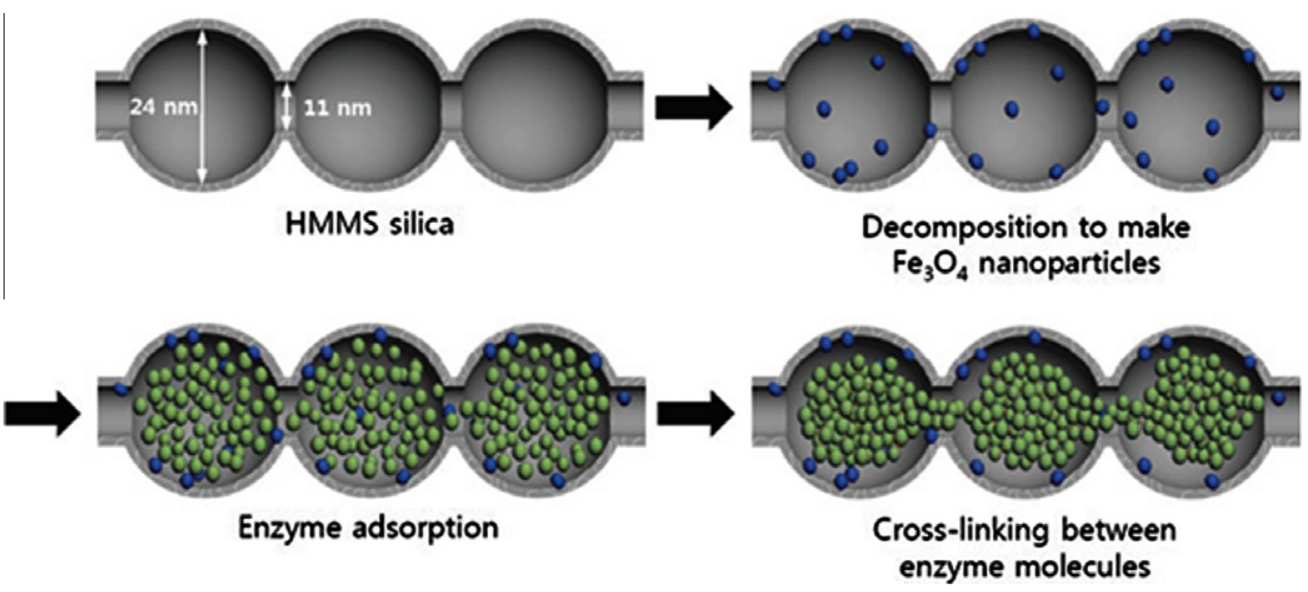

Fig. 6. Schematic diagram for crosslinked enzyme aggregates (CLEA) in superparamagnetic hierarchically-ordered mesocellular mesoporous silica (Lee et al., 2009).

support should be selected deliberately. Broad range of different materials can be used as immobilization support (Table 3 ).

Inorganic supports often obtain a greater stability than organic supports, due to the higher inertness to the reaction conditions like high pressure and temperature. On the other hand, abrasion can occur in stirred vessels. Frequently used inorganic supports (silica, silica derivatives, Celite, aluminum based supports) have been extensively studied and developments have led to the application on both laboratory and industrial scale (Vulfson et al., 2001; Luckarift et al., 2004; Gao et al., 2009).

On the other hand organic supports from a natural source, mostly polysaccharides, have the advantage of a great compatibility with the enzymes. Due to their hydrophilicity, they undergo only weak interactions with the enzyme, leading to a minimal inactivation, but unfortunately it also leads to poor binding and therefore the materials often have to be functionalized. Also the mechanical stability of these materials is rather weak which can be increased by cross-linking. Agarose, cellulose derivatives, and cross-linked dextrans are common used supports from a natural source. Recently, Luo and Zhang (2010) have reported the immobilization of penicillin $G$ acylase in the magnetic cellulose porous microspheres. It was shown that the spherical magnetic $\gamma-\mathrm{Fe}_{2} \mathrm{O}_{3}$ nanoparticles were uniformly dispersed and embedded in the cellulose substrate, and the structure and nature of $\gamma-\mathrm{Fe}_{2} \mathrm{O}_{3}$ were perfectly conserved. The immobilized PGA exhibited highly effective catalytic activity, thermal stability, and enhanced tolerance to $\mathrm{pH}$ variations. Furthermore, the cellulose microspheres loaded with the enzymes could be removed and recovered easily by introducing a magnetic field, leading to an acceptable reusability.

Organic synthetic supports, mostly synthetic polymers, are widely used as immobilization supports (Miletić et al., 2010a; Lane et al., 2011). Acrylic resins such as Eupergit ${ }^{\circledR} \mathrm{C}$ are widely used as supports. Eupergit ${ }^{\circledR} \mathrm{C}$ is a macroporous copolymer of $N, N^{\prime}$-methylene-bi-(methacrylamide), glycidyl methacrylate, allyl glycidyl ether and methacrylamide, highly hydrophilic and stable over a wide $\mathrm{pH}$ range. A major drawback of Eupergit ${ }^{\circledR} \mathrm{C}$ is diffusion limitations, the effects of which, as would be expected, are more pronounced in kinetically controlled processes. Similarly, various porous acrylic resins, such as Amberlite XAD-7 and Novozym 435 , are used to immobilize enzymes. A disadvantage of immobilization in this way is that, because it is not covalently bound, the enzyme can be leached from the support in an aqueous medium.

A growing interest in copolymers as immobilization supports can be observed, since by changing the ratio between the comonomers, the properties of the copolymer (hydrophilicity/hydrophobicity, amount of functional groups, mechanical properties, porosity, etc.) can be desirable changed. Therefore custom-made supports for enzyme immobilization for all kinds of different purposes can be produced.

Macroporous copolymers can be obtained as spherical beads by suspension copolymerization, or in the form of monoliths prepared in an unstirred mold. Among other factors, the applicability of macroporous copolymers to a great extent depends on their porosity. For that reason, the knowledge of the mechanism of porous structure formation and the ability of optimization of porosity parameters (pore size distribution, specific pore volume, specific surface area, and average pore diameter) is needed for designing the copolymers with desired performances.

The term macroporous copolymers designate materials prepared in the presence of a pore-forming agent (inert component, porogen), having a permanent well-developed porous structure even in the dry state (Seidl et al., 1967). As proposed by Kun and Kunin (1968), the beads present agglomerate of microspheres (100$200 \mathrm{~nm})$. Each microsphere consists of smaller nuclei $(10-20 \mathrm{~nm})$, which are often fused. The most substantial contribution to the surface area comes from the micropores with diameters smaller than $2 \mathrm{~nm}$ and by mesopores ranging from 2 to $50 \mathrm{~nm}$. Large macropores with diameters over $50 \mathrm{~nm}$, located in between agglomerates, insignificantly influence the surface area. Macroporous structure appears as a result of the phase separation, which occurs during

Table 3

Frequently used immobilization supports.

\begin{tabular}{|c|c|c|c|}
\hline Support & Advantages & Disadvantages & Samples \\
\hline Inorganic supports & $\begin{array}{l}\text { Greater stability than organic } \\
\text { supports }\end{array}$ & Abrasion can occur in stirred vessels & $\begin{array}{l}\text { Silica and silica derivatives, Celite, aluminum based } \\
\text { supports }\end{array}$ \\
\hline $\begin{array}{l}\text { Organic support from natural } \\
\text { sources }\end{array}$ & $\begin{array}{l}\text { Good compatibility with } \\
\text { enzymes }\end{array}$ & Poor binding, weak mechanical stability & Polysaccharides \\
\hline Organic synthetic supports & Custom-made supports & $\begin{array}{l}\text { Solid-liquid mass transfer, diffusion } \\
\text { limitation }\end{array}$ & Synthetic polymers \\
\hline
\end{tabular}


the polymerization of a monomer mixture containing appropriate amounts of crosslinking monomer and inert component being a low-molecular weight substance (good solvent, a poor solvent for synthesized copolymer or binary mixture), or a linear polymer. An inert component should be soluble in the organic phase and insoluble in the aqueous phase, chemically inert towards the components of the reaction mixture and easily extractable from the synthesized copolymer.

When the inert component is a non-solvent for the synthesized copolymer, phase separation takes place and the macroporous structure is formed. On the other hand, in the presence of a good solvent, two kinds of pore structure can be obtained - gel or macroporous. At low content of the crosslinking agent, the final structure is expanded gel. If the crosslinking agent and dilution degree are both high, a macroporous copolymer is obtained. In the presence of binary mixture of solvent and non-solvent, the formed copolymers have the intermediary characteristics.

The literature offers different approaches for explaining the pore structure formation process. Some authors consider that the differences in the Hildebrand's solubility parameters of the copolymer and the inert component can be used as an indication of the inert component influence on the porous structure of copolymers (Ahmed et al., 2004). Multiparameter approaches (like Hansen's three-dimensional solubility parameter) are considered as much more successful, although they suffer from interpretation complexity and graphic difficulty of displaying the dependent variable as a fourth dimension in the space. Nevertheless, it was observed that difference in porous structure of formed copolymers cannot be explained merely on the basis of the single- or multiparameter approaches. The reason is that properties of components of the system change continuously during the copolymerization (Jovanović et al., 1996). Since the monomers are consumed, only the inert component remains as the liquid component, shifting the overall solubility of the monomer-inert component mixture.

Apart from poly(styrene-co-divinyl benzene) copolymers, which have been studied in details for several decades, the macroporous morphology and formation of porous structure have been investigated for glycidylmethacrylate based copolymers crosslinked with DVB or various methacrylates (Horák et al., 1981; Jovanović et al., 1996; Ferreira et al., 2003; Wang et al., 2007). Horák et al. (1981) were first to show that macroporous poly(glycidyl methacrylate-co-ethylene glycol dimethacrylate) [poly(GMAco-EGDMA)] can be obtained by suspension copolymerization when an inert component (mixture of cyclohexanol as solvent and dodecanol as non-solvent for copolymer) is present in the monomer mixture. Later on, it was showed that instead dodecanol, other aliphatic alcohols (like tetradecanol and hexadecanol) could be used in mixture with cyclohexanol in order to obtain macroporous poly(GMA-co-EGDMA) (Jovanović et al., 1996). As a general rule, the porous structure of poly(GMA-co-EGDMA) can be controlled by the type and the amount of the inert component and the type and the amount of crosslinking monomer in the reaction mixture.

Due to their controllable porosity, hydrophilicity, chemical stability, and possibility of surface chemistry tailoring by introducing of various functional groups, macroporous GMA based copolymers were successfully used as heavy metals (Nastasović et al., 2009) and textile dye sorbents (Sandić et al., 2011), chromatography stationary phases (Ferreira et al., 2003) as well as for enzyme immobilization (Miletić et al., 2009a,b, 2011).

Another option for efficient enzyme immobilization using copolymeric systems is electro spinning. Dai et al. (2011) covalently immobilized CALB onto the poly[acrylonitrile-co-(glycidyl methacrylate)] (PANGMA) nanofibrous mats fabricated by electrospinning, and observed significantly increased activity compared with free enzyme powder. The authors observed that the morphology of the nanofibers remains uniform and the structure of nanomat remains complete after CALB immobilization reaction. Moreover, some small agglomerations of CALB on the surface of the nanofibers after enzyme immobilization are clearly visible.

Variation in comonomer composition of epoxy-activated polymer films composed of poly(glycidyl methacrylate/butyl methacrylate/hydroxyethyl methacrylate) were prepared, in order to explore the relationships between surface wettability and CALB binding to surfaces (Chen et al., 2008).

\section{Concluding remarks}

Enzymatic polymerizations are an emerging research area with not only enormous scientific and technological promise, but also a tremendous impact on environmental issues. It can be envisioned that the whole spectrum of polymeric materials from commodity plastics to specialized functional macromolecules will benefit from these new synthesis methods. As many of the polymeric materials used today and in the future are not water soluble, the biocatalysts used for their synthesis will need to be immobilized to sustain the enzymatic activity. New immobilization routes and supports have to be designed to allow large scale production of polymers via this route.

\section{Acknowledgement}

This work was partly supported by the Ministry of Education and Science of the Republic of Serbia, Project No. III 43009.

\section{References}

Ahmed, M., Malik, M.A., Pervez, S., Raffiq, M., 2004. Effect of porosity on sulfonation of macroporous styrene-divinylbenzene beads. Eur. Polym. J. 40, 1609-1613.

Buchholz, K., Kasche, V., Bornscheuer, U.T., 2005. Biocatalysts and Enzyme Technology. Wiley-VCH, Weinheim.

Cao, L., van Langen, L., Sheldon, R.A., 2003. Immobilised enzymes: carrier-bound or carrier-free? Curr. Opin. Biotechnol. 14, 387-394.

Carleysmith, S.W., Lilly, M.D., 1979. Deacylation of benzylpenicillin by immobilized penicillin acylase in a continuous four-stage stirred-tank reactor. Biotechnol Bioeng. 21, 1057-1073.

Chen, B., Miller, E.M., Miller, L., Maikner, J.J., Gross, R.A., 2007a. Effects of macroporous resin size on Candida antarctica lipase B adsorption, fraction of active molecules, and catalytic activity for polyester synthesis. Langmuir 23 , 1381-1387.

Chen, B., Miller, M.E., Gross, R.A., 2007b. Effects of porous polystyrene resin parameters on Candida antarctica lipase B adsorption, distribution, and polyester synthesis activity. Langmuir 23, 6467-6474.

Chen, B., Pernodet, N., Rafailovich, M.H., Bakhtina, A., Gross, R.A., 2008. Protein immobilization on epoxy-activated thin polymer films: effect of surface wettability and enzyme loading. Langmuir 24, 13457-13464.

Cheng, H.N., Gross, R.A. (Eds.), 2010. Green Polymer Chemistry: Biocatalysis and Biomaterials. ACS Symposium Series. vol. 1043, American Chemical Society.

Cheng, H.N., 2010. Enzyme-catalyzed synthesis of polyamides and polypeptides. In: Loos, K. (Ed.), Biocatalysis in Polymer Chemistry. Wiley-VCH, Weinheim, pp. 131-141.

Dai, T., Miletić, N., Loos, K., Elbahri, M., Abetz, V., 2011. Electrospinning of poly[acrylonitrile-co-(glycidyl methacrylate)] nanofibrous mats for the immobilization of Candida antarctica lipase B. Macromol. Chem. Phys. 212 319-327.

Cruz-Silva, R., Roman, P., Romera, J., 2010. Enzymatic synthesis of polyaniline and other electrically conductive polymers. In: Loos, K. (Ed.), Biocatalysis in Polymer Chemistry. Wiley-VCH, Weinheim, pp. 187-210.

Dyal, A., Loos, K., Noto, M., Chang, S.W., Spagnoli, C., Shafi, K., Ulman, A., Cowman M., Gross, R.A., 2003. Activity of Candida rugosa lipase immobilized on $\gamma-\mathrm{Fe}_{2} \mathrm{O}_{3}$ magnetic nanoparticles. J. Am. Chem. Soc. 125, 1684-1685.

Fernandez-Lorente, G., Terreni, M., Mateo, C., Bastida, A., Fernandez-Lafuente, R. Dalmases, P., Huguet, J., Guisan, J.M., 2001. Modulation of lipase properties in macro-aqueous systems by controlled enzyme immobilization: enantioselective hydrolysis of a chiral ester by immobilized Pseudomonas lipase. Enzyme Microb. Technol. 28, 389-396.

Ferreira, A., Bigan, M., Blondeau, D., 2003. Optimization of a polymeric HPLC phase: poly(glycidyl methacrylate-co-ethylene dimethacrylate): influence of the polymerization conditions on the pore structure of macroporous beads. React. Funct. Polym. 56, 123-136. 
Gao, S., Wang, Y., Wang, T., Luo, G., Dai, Y., 2009. Immobilization of lipase on methyl-modified silica aerogels by physical adsorption. Bioresour. Technol. 100 996-999.

Gross, R.A., Kumar, A., Kalra, B., 2001. Polymer synthesis by in vitro enzyme catalysis. Chem. Rev. 101, 2097-2124.

Grubhofer, N., Schleith, L., 1954. Die Spaltung von Racemischer Mandelsäure mit einem optisch aktiven Anionenaustauscher. Hoppe-Seyler's Z. Physiol. Chem. 296, 262-266.

Gutman, A.L., Zuobi, K., Boltansky, A., 1987. Enzymatic lactonisation of $\gamma-$ hydroxyesters in organic solvents. Synthesis of optically pure $\gamma$ methylbutyrolactones and $\gamma$-phenylbutyrolactone. Tetrahedron Lett. 28 (33), 3861-3864.

Hedin, S.G., 1915. Grundzüge der Physikalischen Chemie ih ihrer Beziehung zur Biologie. J.F. Bergmann Verlag, Wiesbaden.

Hollmann, F., 2010. Enzymatic polymerization of vinyl polymers. In: Loos, K. (Ed.), Biocatalysis in Polymer Chemistry. Wiley-VCH, Weinheim, pp. 143-163.

Horák, D., Švec, F., Bleha, M., Kálal, J., 1981. Reactive polymers XXXV. The effect of polymerization conditions on the specific surface area of macroporous copolymers from glycidyl methacrylate-ethylene dimethacrylate. Angew. Makromol. Chem. 95, 109-111.

Hwang, E.T., Lee, H., Kim, J.H., Tatavarty, R., Gu, M.B., 2011. Highly-stable magnetically-separable organic-inorganic hybrid microspheres for enzyme entrapment. J. Mater. Chem. 21, 6491-6493.

Jovanović, S., Nastasović, A., Jovanović, N., Jeremić, K., 1996. Targeted porous structure of macroporous copolymers based on glycidyl methacrylate. Mater Sci. Forum 214, 155-162.

Knani, D., Gutman, A.L., Kohn, D.H., 1993. Enzymatic polyesterification in organic media. Enzyme-catalyzed synthesis of linear polyesters. I. Condensation polymerization of linear hydroxyesters. II. Ring-opening polymerization of $\varepsilon$ caprolactone. J. Polym. Sci. Pt A: Polym. Chem. 31, 1221-1232.

Krajewska, B., 2004. Application of chitin- and chitosan-based materials for enzyme immobilizations: a review. Enzyme Microb. Technol. 35, 126-139.

Křenkova, J., Foret, F., 2004. Immobilized microfluidic enzymatic reactors. Electrophoresis 25, 3550-3563.

Kobayashi, S., Ritter, H., Kaplan, D., 2006. Enzyme-Catalyzed Synthesis of Polymers. Springer-Verlag, Berlin

Kobayashi, S., Makino, A., 2009. Enzymatic polymer synthesis: an opportunity for green polymer chemistry. Chem. Rev. 109, 5288-5353.

Kovalenko, G.A., Perminova, L.V., Chuenko, T.V., Rudina, N.A., 2009. Adsorptive immobilization of enzymatic active substances on alumina-silica foam coated by carbon nanofibers. Carbon 47, 420-427.

Kumar, S., Mohan, U., Kamble, A.L., Pawar, S., Banerjee, U.C., 2010. Cross-linked enzyme aggregates of recombinant Pseudomonas putida nitrilase for enantioselective nitrile hydrolysis. Bioresour. Technol. 101, 6856-6858.

Kun, K.A., Kunin, R., 1968. Macroreticular resins. III. Formation of macroreticular styrene-divinylbenzene copolymers. J. Polym. Sci. A-1 6, 2689-2701.

Lalonde, J., Margolin, A., 2002. Immobilization of enzymes. In: Drauz, K., Waldmann, H. (Eds.), Enzyme Catalysis in Organic Chemistry, second ed. Wiley-VCH, Weinheim, pp. 163-184.

Lane, S.M., Kuang, Z., Yom, J., Arifuzzaman, S., Genzer, J., Farmer, B., Naik, R., Vaia, R.A., 2011. Poly(2-hydroxyethyl methacrylate) for enzyme immobilization: impact on activity and stability of horseradish peroxidase. Biomacromolecules $12,1822-1830$

Lee, J., Na, H.B., Kim, B.C., Lee, J.H., Lee, B., Kwak, J.H., Hwang, Y., Park, J.G., Gu, M.B., Kim, J., Joo, J., Shin, C.H., Grate, J.W., Hyeon, T., Kim, J., 2009. Magnetically-separable and highly-stable enzyme system based on crosslinked enzyme aggregates shipped in magnetite-coated mesoporous silica. J. Mater. Chem. 19, 7864-7870.

Loos, K., 2010. Biocatalysis in Polymer Chemistry. Wiley-VCH, Weinheim.

Luckarift, H.R., Spain, J.C., Naik, R.R., Stone, M.O., 2004. Enzyme immobilization in a biomimetic silica support. Nat. Biotechnol. 22, 211-213.

Luo, X., Zhang, L., 2010. Immobilization of penicillin G acylase in epoxy-activated magnetic cellulose microspheres for improvement of biocatalytic stability and activities. Biomacromolecules 11, 2896-2903.

Manecke, G., Singer, S., 1960. Über einige chemische umsetzungen am polyaminostyrol. Makromol. Chem. 37, 119-142.

Mateo, C., Fernandez-Lorente, G., Abian, O., Fernandez-Lafuente, R., Guisan, J.M. 2000. Multifunctional epoxy supports: a new tool to improve the covalent immobilization of proteins. The promotion of physical adsorptions of proteins on the supports before their covalent linkage. Biomacromolecules 1, 739-745.

Mateo, C., Palomo, J.M., Fernandez-Lorente, G., Guisan, J.M., Fernandez-Lafuente, R. 2007a. Improvement of enzyme activity, stability and selectivity via immobilization techniques. Enzyme Microb. Technol. 40, 1451-1463.

Mateo, C., Grazú, V., Pessela, B.C.C., Montes, T., Palomo, J.M., Torres, R., Lopez-Gallego, F., Fernandez-Lafuente, R., 2007b. Advances in the design of new epoxy supports for enzyme immobilization-stabilization. Biochem. Soc. Trans. 35, 1593-1601.

Matijošytè, I., Arends, I.W.C.E., de Vries, S., Sheldon, R.A., 2010. Preparation and use of cross-linked enzyme aggregates (CLEAs) of laccases. J. Mol. Catal. B: Enzym. $62,142-148$

Micheel, F., Ewers, J., 1949. Synthese von verbindungen der cellulose mit eiweißstoffen. Makromol. Chem. 3, 200-209.

Miletić, N., Bos, C., Loos, K., 2009a. Immobilization - a route for improving enzyme performance. In: Nastasović, A., Jovanović, S.M. (Eds.), Polymeric Materials. Research Signpost, Trivandrum, pp. 131-153.

Miletić, N., Vuković, Z., Nastasović, A., Loos, K., 2009b. Macroporous poly(glycidyl methacrylate-co-ethylene glycol dimethacrylate) resins - versatile immobilization supports for biocatalysts. J. Mol. Catal. B: Enzym. 56, 196-201.
Miletić, N., Abetz, V., Ebert, K., Loos, K., 2010a. Immobilization of Candida antarctica lipase B on polystyrene nanoparticles. Macromol. Rapid Commun. 31, 71-71.

Miletić, N., Loos, K., Gross, R., 2010b. Enzymatic polymerization of polyester. In: Loos, K. (Ed.), Biocatalysis in Polymer Chemistry. Wiley-VCH, Weinheim, pp. $83-129$

Miletić, N., Vuković, Z., Nastasović, A., Loos, K., 2011. Effect of Candida antarctica lipase B immobilization on the porous structure of the carrier. Macromol. Biosci. $11,1537-1543$.

Nastasović, A., Sandić, Z., Suručić, Lj., Maksin, D., Jakovljević, D., Onjia, A., 2009. Kinetics of hexavalent chromium sorption on amino-functionalized macroporous glycidyl methacrylate copolymer. J. Hazard. Mater. 171, 153-159.

Nemzer, L.R., Schwartz, A., Epstein, A.J., 2010. Enzyme entrapment in reprecipitated polyaniline nano- and microparticles. Macromolecules 43, 4324-4330.

Okumara, S., Iwai, M., Tominaga, Y., 1984. Synthesis of ester oligomer by Aspergillus niger lipase. Agric. Biol. Chem. 48, 2805-2808.

Palmans, A.R.A., Heise, A., 2010. Enzymatic Polymerization, vol. 237. SpringerVerlag, Berlin.

Palomo, J.M., Munoz, G., Fernandez-Lorente, G., Mateo, C., Fernandez-Lafuente, R., Guisan, J.M., 2002. Interfacial adsorption of lipases on very hydrophobic support (octadecyl-Sepabeads): immobilization, hyperactivation and stabilization of the open form of lipases. J. Mol. Catal. B: Enzym. 19-20, 279-286.

Pavlidis, I.V., Tzialla, A.A., Enotiadid, A., Stamatis, H., Gournis, D., 2010. Enzyme immobilization on layered and nanostructured materials. In: Loos, K. (Ed.), Biocatalysis in Polymer Chemistry. Wiley-VCH, Weinheim, pp. 35-63.

Pchelintsev, N.A., Youshko, M.I., Švedas, V.K., 2009. Quantitative characteristic of the catalytic properties and microstructure of cross-linked enzyme aggregates of penicillin acylase. J. Mol. Catal. B: Enzym. 56, 202-207.

Quiocho, F.A., Richards, F.M., 1964. Intermolecular cross linking of a protein in the crystalline state: carboxypeptidase-A. Proc. Natl. Acad. Sci. 52, 833-839.

Quiocho, F.A., Richards, F.M., 1966. The enzymic behavior of carboxypeptidase-A in the solid state. Biochemistry 5, 4062-4076.

Reetz, M.T., Zonta, A., Simpelkamp, J., 1995. Efficient immobilization of lipases by entrapment in hydrophobic sol-gel materials. Biotechnol. Bioeng. 49, 527-534.

Reetz, M.T., Tielmann, P., Wiesenhofer, W., Konen, W., Zonta, A., 2003. Second generation sol-gel encapsulated lipases: robust heterogeneous biocatalysts. Adv. Synth. Catal. 345, 717-728.

Roy, J.J., Abraham, T.E., 2004. Strategies in making cross-linked enzyme crystals. Chem. Rev. 104, 3705-3721.

Sandić, Z.P., Nastasović, A.B., Jović-Jovičić, N.P., Milutinović-Nikolić, A.D., Jovanović, D.M., 2011. Sorption of textile dye from aqueous solution by macroporous amino-functionalized copolymer. J. Appl. Polym. Sci. 121, 234-242.

Santos, J.C., Nunes, G.F.M., Moreira, A.B.R., Perez, V.H., de Castro, H.F., 2007. Characterization of Candida rugosa lipase immobilized on $\operatorname{poly}(\mathrm{N}$ methylolacrylamide) and its application in butyl butyrate synthesis. Chem. Eng. Technol. 30, 1255-1261.

Saunders, P., Brask, J., 2010. Improved immobilization supports for Candida antarctica lipase B. In: Loos, K. (Ed.), Biocatalysis in Polymer Chemistry. Wiley-VCH, Weinheim, pp. 65-82.

Seidl, J., Malinsky, J., Dušek, K., Heitz, W., 1967. Makroporöse Styrol-DivinylbenzolCopolymere und ihre Verwendung in der Chromatographie und zur Darstellung von Ionenaustauschern. Adv. Polym. Sci. 5, 113-213.

Tischer, W., Wedekind, F., 1999. Immobilized enzymes: methods and applications. In: Fressner, W.D. (Ed.), Biocatalysis-From Discovery to Application. SpringerVerlag, Berlin, pp. 95-126.

Tosa, T., Mori, T., Fuse, N., Chibata, I., 1969. Studies on continuous enzyme reactions. Part V. Kinetics and industrial application of aminoacylase column for continuous optical resolution of acyl-DL-amino acids. Agric. Biol. Chem. 33, 1047-1052.

Uyama, H., Kobayashi, S., 1993. Enzymatic ring-opening polymerization of lactones catalyzed by lipase. Chem. Lett. 22, 1149-1150.

Uyama, H., Kobayashi, S., 2006. Enzymatic synthesis of polyesters via polycondensation. In: Kobayashi, S., Ritter, H., Kaplan, D. (Eds.), EnzymeCatalyzed Synthesis of Polymers. Springer-Verlag, Berlin, pp. 133-158.

Uyama, H., 2010. Enzymatic polymerization of phenolic monomers. In: Loos, K. (Ed.), Biocatalysis in Polymer Chemistry. Wiley-VCH, Weinheim, pp. 165-185.

van der Vlist, J., Loos, K., 2010a. Enzymatic polymerizations of polysaccharides. In: Loos, K. (Ed.), Biocatalysis in Polymer Chemistry. Wiley-VCH, Weinheim, pp. 211-246.

van der Vlist, J., Loos, K., 2010b. Transferases in polymer chemistry. In: Palmans, A.R.A., Heise, A. (Eds.), Enzymatic Polymerization. Springer-Verlag, Berlin, pp. 21-54.

Vidinha, P., Augusto, V., Almeida, M., Fonseca, I., Fidalgo, A., Ilharco, L., Cabral, J.M.S., Barreiros, S., 2006. Sol-gel encapsulation: an efficient and versatile immobilization technique for cutinase in non-aqueous media. J. Biotechnol. $121,23-33$

Vulfson, E.N., Halling, P.J., Holland, H.L., 2001. Enzymes in Nonaqueous Solvents: Methods and Protocols. Humana Press, Totowa.

Wang, L., Qi, T., Gao, Z., Zhang, Y., Chu, J., 2007. Synthesis of $N$-methylglucamine modified macroporous poly(GMA-co-TRIM) and its performance as a boron sorbent. React. Funct. Polym. 67, 202-209.

Zhang, Y., Wu, H., Li, L., Li, J., Jiang, Z., Jiang, Y., Chen, Y., 2009. Enzymatic conversion of Baicalin into Baicalein by $\beta$-glucuronidase encapsulated in biomimetic coreshell structured hybrid capsules. J. Mol. Catal. B: Enzym. 57, 130-135.

Zhang, Y., Xu, J., Yuan, Z., Xu, H., Yu, Q., 2010. Artificial neural network-genetic algorithm based optimization for the immobilization of cellulase on the smart polymer Eudragit L-100. Bioresour. Technol. 101, 3153-3158. 